\title{
ERRATUM
}

Open Access

\section{Erratum to: Reconstruction of a 2D seismic wavefield by seismic gradiometry}

Takuto Maeda ${ }^{1 *}$, Kiwamu Nishida$^{1}$, Ryota Takagi ${ }^{2}$ and Kazushige Obara ${ }^{1}$

\section{Erratum}

In the publication of this article (Maeda et al. 2016), there was an error in the Real-world application: 2005 Off-Tohoku outer-rise earthquake section which was published with an incorrect day an earthquake occured and moment magnitude scale. The error: 'Next, we applied the same technique to real observations made during an earthquake that occurred in the east off Tohoku on 16 August 2005 (Mw 7.2).' Should instead read: 'Next, we applied the same technique to real observations made during an earthquake that occurred in the east off Tohoku on 14 November 2005 (Mw 7.0).' This has now been included in this erratum.

\footnotetext{
Author details

${ }^{1}$ Earthquake Research Institute, The University of Tokyo, 1-1-1 Yayoi, Bunkyo-ku, Tokyo 113-0032, Japan. ${ }^{2}$ Research Center for Prediction of Earthquakes and Volcanic Eruptions, Graduate School of Science, Tohoku University, Sendai 980-8578, Japan.
}

Received: 11 November 2016 Accepted: 11 November 2016

Published online: 25 November 2016

\section{Reference}

Maeda T, Nishida K, Takagi R, Obara K (2016) Reconstruction of a 2D seismic wavefield by seismic gradiometry. Prog Earth Planet Sci 3:1. doi:10.1186/s40645-016-0107-4

\footnotetext{
* Correspondence: maeda@eri.u-tokyo.ac.jp

'Earthquake Research Institute, The University of Tokyo, 1-1-1 Yayoi, Bunkyo-ku, Tokyo 113-0032, Japan
} 